\title{
The Application of Hierarchical Teaching Method on Basketball Teaching in Colleges
}

\author{
Fei Liu \\ University of Electronic Science and Technology of China, Chengdu, Sichuan, 611731
}

Keywords: Hierarchical teaching method, university, basketball teaching, application exploration.

\begin{abstract}
With the deepening of educational reform, the requirements for the development of college physical education are also changing. Compared with the traditional college physical education, the new curriculum under the background of basketball teaching more emphasis on cultivating students' comprehensive sports quality, it emphasizes the student-oriented basketball teaching philosophy, so hierarchical teaching method is widely used in college basketball Teaching. In order to realize the application of hierarchical teaching method in college basketball, this article discusses the necessity of the application of hierarchical teaching method in college basketball teaching, and the problems existing in the teaching of hierarchical teaching method, The characteristics put forward a few specific strategies to facilitate the better play the role of hierarchical teaching in college basketball teaching.
\end{abstract}

\section{Introduction}

Hierarchical teaching method, from the surface to understand is the level of teaching, step by step progressive teaching methods, college basketball teaching is an important teaching methods. Basketball teaching is in the application of hierarchical teaching method, to student-oriented, with the development of the eyes to see every student. To understand the differences in the development of each student, and according to different students to develop different scientific and personalized basketball teaching methods, to fully mobilize the enthusiasm of students to enhance students' basketball skills and comprehensive literacy, to achieve the innovative development of college basketball teaching.

\section{The Connotation of Hierarchical Teaching Method}

The hierarchical teaching method refers to the teachers in the actual teaching process, according to the different needs of different students and the actual situation to develop the corresponding learning plan, the teaching of stratification, different levels of students to carry out targeted guidance. The purpose of hierarchical teaching method is to divide the teaching level so that different levels of students can get good development, so as to promote the overall teaching level, so that the effect of teaching can be enhanced. Hierarchical teaching method can effectively improve students' autonomy and enthusiasm for learning, so that students can develop in all directions in teaching. Hierarchical teaching of the starting point is low, so easy to improve the enthusiasm of students to learn to achieve further development of superior students to promote the development of secondary students and weak students.

\section{The Application of Hierarchical Teaching Method}

Basketball classes and other subjects compared to its own unique characteristics. In the basketball teaching for students, the basketball teacher not only by virtue of their own excellent theoretical knowledge of basketball, but also have the ability to bring the theory into practice teaching, so from this point of view, college basketball is a requirement to have the theory and practice two aspects of the comprehensive disciplines. Because the college basketball teaching has a 
very high degree of difficulty for students, so some students in the process of learning basketball is very difficult, especially some of the poor quality of the students, it is unable to adapt to such a difficult teaching process, Which led to the overall quality of basketball teaching is not very optimistic. From the composition of the current students, there are different differences between students, so that students can not guarantee the balance of the body's differences, so in this can not avoid differences between students in the case, the various university teachers will have to adjust their teaching methods, to find a hierarchical and differentiated teaching methods, with this new teaching methods to adapt to the differences between different students, to the maximum to meet the development needs of each student, in order to improve the basketball The level of teaching.

Learning interest is an important foundation for learning a course. In college basketball teaching, because the individual differences of students, it will lead some students can not keep up with the progress of the tutorial, there will be psychological gap, because of this psychological gap, will make students lose their enthusiasm for learning so as to learn basketball has a bad mentality, which for the college basketball teaching quality improvement left a lot of hidden dangers. In such circumstances, it is necessary to college basketball teaching students to be based, according to the different needs of students, teaching methods to adjust. Hierarchical teaching method this method is just able to meet the practical needs of colleges and universities with a hierarchical teaching method to adapt to the development of each student.

\section{The Current Situation of College Basketball Teaching}

In Chinese colleges and universities is under normal circumstances, non-sports college basketball in the elective courses. The elective course in the university means that the student can choose according to his own interest, choose the course, the professional or the professional, and every school year, the student can re-select and adjust the elective course from the purpose and motivation of the students' elective basketball courses, some students are choosing to play basketball lessons because they love basketball. However, there are many students who have finished school or have curiosity about basketball. In this case, will make the basketball elective students there is a big difference between the students. Students from the conditions of their own point of view, although some students have not come into contact with basketball, but have a good basketball talent, and its own physical fitness is better, so you can quickly grasp the basics of basketball basic skills, and Some students may be due to physical fitness reasons, in the learning of basketball skills when there are some difficulties, learning more slowly, this reason is also led to a certain difference in the level of student basketball reasons. These factors are not conducive to the teacher in the basketball teaching, basketball teaching in the future development of a great obstacle.

In the college elective model, often those who are interested in basketball students will elect elective basketball courses, and these students usually must also often contact with basketball, often do basketball, these students have the basics and skills of basketball. Therefore, in the daily basketball teaching, these have been exposed to basketball students will teach the teacher's knowledge presented a negative state, they will think that the teacher is very boring knowledge, not fully understand the importance of the basic skills of basketball, thus ignoring the study of basketball technology. This will make these students to learn the basic skills of basketball are not high enthusiasm hinder the development of students, making the quality of teaching greatly reduced.

Some students in the basic skills of basketball learning process of negative neglect of the situation, so that they can not fully grasp the basketball technology, in the actual basketball activities or training process, can not fully play in the basketball technology, so that they can not In the actual basketball activities in the implementation of teacher tactics, tactical effect is not obvious enough. This will result in students in the implementation of tactical tasks when the lack of enthusiasm, and even doubt on the tactics, which the future development of tactical teaching is very unfavorable. 


\section{The Problems in Layered Teaching Method}

The upsurge of national fitness has promoted the further development of basketball, which provides a good environment for the development of basketball teaching in colleges and universities. However, because of the constraints of the traditional teaching model, sports has not been the attention of people, resulting in Chinese student groups physical backwardness, so the development of basketball teaching has brought serious obstacles. In addition, the basketball class as a sport in the optional course which contains a lot of faculty students, each student's understanding of the basics of basketball are different, each person's own sports base is not the same, so it affected the development of basketball teaching.

By the traditional teaching model, college basketball teaching is still using a uniform teaching method and the teacher to explain the whole, students practice, and with a fixed standard as the main way of evaluation, so deepen the college basketball the contradiction in teaching. In such a single teaching mode, the individual differences in physical quality of students and the basic understanding of basketball, these are inconsistent with the teaching process, the knowledge of basketball and basketball skills to master the students are in the passive acceptance process. In this case, the student's initiative and creativity can not be played, seriously affecting the development and growth of students. In addition, in such a single teaching mode, the teacher's teaching ability can not be reflected, not to enhance the teacher's teaching creativity is also limited to a single teaching mode, can not adapt to the development of the times, hinder the hierarchical teaching the application of law in college basketball teaching has affected the development of college basketball teaching.

With the continuous development of educational environment, college basketball teaching environment and teaching needs are constantly changing, so, in the new era, the teacher's education quality also put forward new requirements. However, the college basketball teacher for a long time by the traditional concept of the impact of their educational concepts and ability are relatively backward. First of all, in the current college basketball teaching, there is a unified teaching model, in the teaching of basketball in this teaching method still exists, the development of college basketball teaching and innovation have a negative impact. In addition, continue to follow the traditional theory of basketball teaching, the lack of new theory and teaching methods of research, so that the current college basketball teacher's teaching ability is more backward, a serious impact on the application of hierarchical teaching for college basketball teaching Innovation has caused serious obstacles.

\section{The Application of Hierarchical Teaching Method in College Basketball Teaching}

The advantage of applying the tiered teaching method is that this method can vary according to the different students and develop different learning goals and learning plans. Therefore, in the hierarchical teaching, the principle of individualization is the teaching of college basketball. On the basis of the principle of individualization, the basketball teaching in colleges and universities should not make a unified teaching goal in the same way, aim at the basic knowledge of basketball and the different physical quality, formulate and arrange specific teaching contents and teaching objectives. In the teaching of basketball to teach each other, vary, so that different students can get a good development.

In the college basketball teaching application of hierarchical teaching method, mainly to improve the quality of college basketball teaching and teaching efficiency, so the use of hierarchical teaching method, we should pay attention to the principle of effectiveness. Under the influence of this principle, the university basketball teaching efforts to do according to different students to develop different learning programs for individual students to provide effective learning and training to promote each student can all-round development. Not only for the level of teaching, but also to improve the overall level of teaching to ensure that different students have a corresponding teaching objectives and teaching requirements. 
In the college basketball teaching effective application of hierarchical teaching method and it can not be separated from the scientific level of teaching division. In the application of hierarchical teaching method, the teacher according to the existing teaching resources, make the greatest efforts to divide the teaching into multiple levels. For example, according to the different students of physical fitness and physical differences in group teaching, for students to develop appropriate training content, is that every student can get a good development. At the same time, we should pay attention to the overall level of teaching content, the first basic knowledge of the training of students, gradually increased to the team's cooperation and tactical layout and other advanced level, so not only meet the individual differences due to students of the development needs, but also to achieve the quality of teaching and efficiency of the increase.

\section{Conclusion}

We understand that, according to the above, hierarchical teaching method in college basketball teaching has important significance. The application of hierarchical teaching method, one can adapt to the development of new curriculum, timely adjustment of teaching concepts and teaching forms and other requirements, can provide help for its own innovation and development. The second is to cultivate the basic basketball skills of college students to improve their overall quality of sports laid a good foundation. In the process of teaching basketball in colleges and universities, we should pay attention to the shortcomings of our own shortcomings and summarize the connotation of hierarchical teaching method. We should take the principle of individuality as the principle of persistence and actively promote the teaching of college basketball The better development of the system, to improve the professionalism of basketball teachers and their teaching ability, to do to maximize the promotion of hierarchical teaching methods and college basketball teaching integration, and strive to achieve the better development of college basketball teaching.

\section{References}

[1] Ma Hongjun. Stratified teaching method in our college basketball elective course in the application research[J]. Contemporary sports science and technology, 2015, 5 (31): 26-27.

[2] DING Yi-fu.Application of hierarchical teaching method in college basketball teaching [J]. Contemporary Sports Science and Technology, 2016,6 (11): 50-51. [2017-08-16]. DOI: 10.16655 / j .cnki.2095-2813.2016.11.050

[3] Jiang Yan. Stratified teaching method in the use of basketball teaching in colleges and universities[J]. Sports World (Late Journal), 2013, (05): 101-102.

[4] Fan Li.Application of cooperative teaching method in college basketball teaching [J]. Journal of Suzhou Education College, 2014,17 (04): 168-170. [2017-08-16]. DOI: 10.13985 / j. Cnki.34-1227 / c.2014.04.063

[5] Zeng Qizhi. On the use of hierarchical teaching method in college basketball teaching[J]. Contemporary Sports Science and Technology, 2014,4 (25): 62-63.

[6] Gao Libo. Stratified teaching method in college basketball teaching experiment[J]. Science and Technology Information (Academic Research), 2008, (10): 225-226.

[7] Liu Gang. Stratified teaching in college basketball teaching application [J]. Contemporary sports science and technology, 2015, (16): 108-109.

[8] Chen Wenjie. Study on the Application of Hierarchical Teaching Method in College Basketball Elective Course in China [J]. Sport World (2017, (02): 102-103.

[9] Fu Fanfei. Analysis of hierarchical teaching method in the use of college basketball teaching[J]. Youth Sports, 2017, (04): 92-93 